[LONDON] Panels of overseas scientists will for the first time help to assess the quality of Britain's best university research, according to Britain's higher-education funding councils. The move is one of several changes to Britain's Research Assessment Exercise (RAE), a regular initiative to assess the quality of university research. The next RAE will begin in April 2001.

"Science is an international activity," says Bahram Bekhradnia, director of policy at the Higher Education Funding Council for England (HEFCE). Funding councils, he adds, will now have the chance to calibrate Britain's research on an international scale.

Each of the RAE's 60 subject panels will choose a corresponding 'virtual' panel of scientists overseas. Members of the overseas panel will not meet physically, but will review all research considered by the UK panel to be worthy of the highest classification.

This is not the first time overseas scientists have been asked to help assess Britain's research; they have occasionally been coopted on to UK-based panels before. But Bekhradnia says such an arrangement proved unworkable for logistical reasons; it was therefore decided to set up separate panels of overseas experts.

Other changes to the previous 1996 exercise include giving Britain's 117 universities longer to prepare their submissions, and giving feedback on performance. Panel chairs will be nominated by the entire outgoing panel, instead of just the outgoing chairman.

From next month, HEFCE will begin to consult universities on how to improve university teaching while retaining high-quality research departments. This is partly in response to the widespread perception among universities that the university funding formula encourages universities to invest in research at the expense of teaching.

The National Committee of Inquiry into Higher Education chaired by Lord Ron Dearing suggested a cash incentive to dissuade mediocre research institutions from diverting resources away from good teaching departments to boost research. But this idea, according to a HEFCE spokeswoman, was not well received.

The RAE is designed to help the highereducation funding councils ensure that their research funds of $£ 826$ million (US $\$ 1.38$ billion) are weighted so that larger amounts of money go to universities whose research departments are the most productive.

It works mainly through peer review, with 60 expert panels assessing 69 subject areas. Each university subject-group is given a quality rating on a seven-point scale, based on an assessment by the panel of each individual member's four best pieces of research.

Subject groups are scored from 1 - the lowest rating - to $5^{\star}$, which indicates that most of the work submitted is equivalent to the best in the world. A score of 3 is divided into two categories: $3 \mathrm{~b}$ indicates that most research is of national excellence; 3 a may also include research of the highest international standard.

Despite the planned changes, the announcement of the new RAE is likely to reopen many of the criticisms prompted by previous assessments. A major concern of the Association of University Teachers, for example, is that the RAE may jeopardize future research talent by cutting off funds from promising but less well-established researchers who are working in low-scoring departments.

But Bekhradnia disagrees, pointing out that money is withheld only from those universities whose departments score below $3 b$, and only for five years.

Other critics believe that the RAE encourages university departments to focus their expertise on areas of national prioritysuch as those identified by the Technology Foresight programme - to attract research

funding, when they should be setting their own research agendas.

This is a particular worry for the Engineering and Physical Sciences Research Council, which already spends around 70 per cent of its budget on Foresight-related activities. David Leech, the council's director of planning, believes that the research councils and the funding councils should maintain a distance from each other in the kinds of research they fund, to ensure diversity within British research.

Diana Garnham, general secretary of the Association of Medical Research Charities, and an RAE assessor, agrees. "It is important for universities to be able to initiate ideas for us [the charities] to respond to. We don't want to direct all of the research."

But again Bekhradnia says such fears are unfounded. "It is up to universities to decide how to spend money they receive from the funding councils," he says. "They may want to give it to their existing centres of excellence. On the other hand, they may want to develop other areas. These are decisions for them, not for us."

EhsanMasood

\title{
Plea for plurality on advice to ministers
}

[LONDON] Britain's top scientific adviser has urged that the full range of scientific advice to governments should be made public and not just a consensus view - in a bid to convey a sense of the different scientific opinions on issues.

Addressing the House of Commons Select Committee on Science and Technology last week, Sir Robert May, the prime minister's chief scientific adviser and head of the Office of Science and Technology, said that public confidence in the scientific advisory system needed to be regained following

controversies such as the bovine spongiform encephalopathy (BSE) crisis.

Trust could be rebuilt if science advisers "consult widely, and consult contrary opinion" when issuing advice, said May. He added that all opinions should be made public, along with - wherever possible advice to politicians based on them.

May acknowledged that civil servants were "uncomfortable" with the approach he was advocating, as it conflicted with the tradition that advice to ministers must remain confidential. But he said that, although there were genuine instances where confidentiality was paramount, "in general, I am for openness and taking risks".

May, who is Royal Society research professor at the University of Oxford and Imperial College, London, made his comments during a hearing at the House of Commons held as part of an inquiry into the

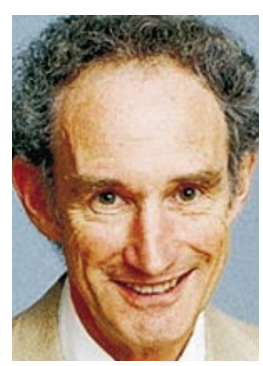

May: need to rebuild public confidence. effectiveness of the scientific advisory system.

May said he was satisfied with the level of scientific awareness among government officials. But BSE provided one example in which research awareness among civil servants could have been better.

With the exception of the agriculture ministry, May said he considered government departments' understanding of relevant scientific issues "exemplary". By contrast, he said the government was less successful in its attempts to gain public confidence in the scientific advisory process.

Not all members of the select committee were convinced by May's remarks. Nigel Beard (Labour, Bexleyheath and Crayford) questioned the perceived benefits of publicizing conflicting views, particularly on issues relating to food safety. $\mathrm{He}$ suggested that this could lead to confusion among the public.

But May said that a commitment to openness and an acknowledgement of differing views had contributed to the success of the government's AIDS awareness campaigns during the late 1980s and early 1990 s. 